\title{
THE INCREASED NEED FOR A PERMANENT PACEMAKER AFTER REOPERATIVE CARDIAC SURGERY
}

Joseph W. Lewis, Jr., MD

Charles R. Webb, MD

Sol D. Pickard, MD

Judith Lehman, RN

Gordon Jacobsen, MS
Objective: The requirement for permanent pacemaker implantation after most initial cardiac surgical procedures generally is less than 3\%. To identify the incidence and factors related to permanent pacemaker need after repeat cardiac surgery, we retrospectively studied 558 consecutive patients undergoing at least one repeat cardiac operation. Method: Univariable and multivariable analyses of comorbidity, preoperative catheterization values, and operative data were performed to identify factors related to pacemaker implantation. Results: In this group, 54 patients $(9.7 \%)$ required a permanent pacemaker. A multivariable model showed a relationship between a permanent pacemaker and tricuspid valve replacement/annuloplasty associated with aortic/mitral valve replacement, preoperative endocarditis, increasing number of reoperations, the degree of hypothermia during cardiopulmonary bypass, and advanced age. Additional univariable predictors of pacemaker need included multiple valve replacement, increased cardiopulmonary bypass and aortic crossclamp times, and aortic valve replacement. Over $90 \%$ of patients who have or have not received permanent pacemaker implantation were in New York Heart Association class I to II, with a mean follow-up time of 6 years. Kaplan-Meier survival curves were statistically similar for both groups at 5 and $\mathbf{1 0}$ years after the operation. Conclusion: Permanent pacemaker implantation was required in 9.7\% of patients undergoing repeat cardiac surgery. This represented approximately a fourfold increase compared with similar primary operations reported in other series. Factors strongly related to this need included valve replacement, preoperative endocarditis, number of reoperations, advanced age, and degree of hypothermia during cardiopulmonary bypass. The need for a permanent pacemaker after reoperations did not result in significant long-term impairment of functional status or longevity compared with those who did not require a permanent pacemaker. (J Thorac Cardiovasc Surg 1998;116:74-81)
In a literature review of 24,729 predominantly first-time cardiac surgical procedures, ${ }^{1-21}$ the need for postoperative permanent pacemaker implantation (PPI) was 2.2\%. For isolated coronary artery bypass grafting, 37 of 4596 patients $(0.8 \%)$ required PPI. PPI was performed in 98 of 2800 (3.5\%) valve

From the Division of Cardiac and Thoracic Surgery, Henry Ford Hospital, Detroit, Mich.

Received for publication Dec. 24, 1996; revisions requested Feb. 20, 1997; revisions received Feb. 13, 1998; accepted for publication Feb. 13, 1998.

Address for reprints: Joseph W. Lewis, Jr., MD, Division of Cardiac and Thoracic Surgery, Henry Ford Hospital, 2799

West Grand Blvd., Detroit, MI 48202.

Copyright (C) 1998 by Mosby, Inc.

$0022-5223 / 98 \$ 5.00+0 \quad \mathbf{1 2 / 1 / 8 9 9 6 3}$ replacements, 132 of $6004(2.2 \%)$ congenital heart defect repairs, and 13 of 118 (11.0\%) orthotopic heart transplantations. To define the incidence and factors relating to PPI after reoperative cardiac surgical procedures, we studied 558 consecutive patients who did receive a permanent pacemaker and who were undergoing at least one repeat operation.

\section{Patients and methods}

A retrospective analysis of patients requiring repeat cardiac surgical procedures between March 1976 and December 1991 was conducted. All patients receiving PPI were included in the PPI group irrespective of their survival status. Those patients with self-limiting bradyarrhythmias that required only temporary pacing were placed in the nonpaced cohort. The remote cutoff date of 
Table I. Permanent pacing needs in reoperative cardiac operations

\begin{tabular}{lcc}
\hline \multicolumn{1}{c}{ Type of operation } & $\begin{array}{c}\text { Total no. } \\
(\%)\end{array}$ & $\begin{array}{c}\text { No. in subgroup } \\
\text { requiring permanent } \\
\text { pacemaker }(\%)\end{array}$ \\
\hline Valve replacement & $293(52.5)^{*}$ & $47(16.0) \dagger$ \\
$\begin{array}{l}\text { Coronary artery bypass } \\
\text { grafting }\end{array}$ & $168(30.1)$ & $4(2.4)$ \\
$\begin{array}{l}\text { Coronary artery bypass } \\
\text { grafting/valve }\end{array}$ & $24(4.3)$ & $1(4.1)$ \\
$\quad$ replacement & & \\
Heart transplantations & $13(2.3)$ & $1(7.7)$ \\
Congenital defects & $6(1.1)$ & $0(0)$ \\
Other \begin{tabular}{l} 
Total \\
\hline
\end{tabular} & $54(9.7)$ & $1(1.8)$ \\
\hline
\end{tabular}

*Percent of all reoperative procedures.

$\dagger$ Percent of patients in specific subgroup of operation requiring permanent pacemaker.

$\ddagger$ Procedures such as left atrial myxoma recurrence, thoracic aorta reoperations, pericardectomy with cardiopulmonary bypass, reoperation for penetrating cardiac trauma.

1976 was chosen because cardioplegic arrest of the heart was introduced at this institution at that time. Although multiple surgeons participated in the care of this group, surgical methods remained remarkably constant during the study period. Pericardial reentry was achieved by median sternotomy; cardiopulmonary bypass was performed with a membrane oxygenator with a crystalloid prime in most instances. Cold crystalloid cardioplegia $\left(10^{\circ} \mathrm{C}\right)$ was used during aortic crossclamping in most of the patients. The degree of systemic cooling during perfusion varied among surgeons. Before cardiopulmonary bypass was discontinued, temporary atrial and ventricular pacing wires were placed in most patients with a sinus mechanism. Those with atrial fibrillation received ventricular leads only. Permanent screw-in epicardial leads were used in those patients with tricuspid procedures or suspected conduction injury during complicated valve reoperations. In this setting, temporary pacing in the immediate perioperative period was accomplished through disposable transcutaneous wires linked to the permanent electrode. Complete heart block or bradyarrhythmias with ventricular rates below 45 to 50 beats/min persisting 7 to 10 days after the operation received permanent pacemakers. Patients were seen in the Pacemaker Clinic 1 week, 1 month, and 3 months after discharge; thereafter, patients were examined every 6 months. Those patients with no $\mathrm{R}$ waves when briefly paced VVI at 30 beats/min were considered pacemaker dependent; they were seen every 3 months. Evaluation at each visit included interrogation of the programmed parameters, telemetry data, and event counters. After the underlying rhythm had been documented, sensing and stimulation thresholds were measured and final settings were programmed according to Pacemaker Clinic guidelines. In addition, transtelephonic monitoring was conducted every 2 months until the generator reached month 36 of service. Thereafter, transtelephonic monitoring was done on a monthly basis until the generator was replaced. Numeric data generated by PPI
Table II. Number of reoperative cardiac surgical procedures

\begin{tabular}{lcccc}
\hline & \multicolumn{4}{c}{ No. of repeat operations } \\
\cline { 2 - 5 } & One & Two & Three & Four \\
\hline Permanent & 54 & $18(p=0.04) *$ & $6(p=0.02) *$ & $1(p=0.2)^{*}$ \\
pacemaker & & & & \\
Nonpaced & 504 & 89 & 16 & 2 \\
Total & 558 & 107 & 22 & 3 \\
${ }^{*} \chi^{2}$ test of association. & & & \\
\end{tabular}

and nonpaced groups were compared by a two-sample unpaired $t$ test. Because of the large number of variables examined, a statistical significance was achieved at $p<$ 0.01 . Categoric data were analyzed by the $\chi^{2}$ test of association. Survival information for the two groups was compared by Kaplan-Meier curves with the log-rank test. Possible factors related to the need for PPI with $p<0.20$ from univariable comparisons were entered into a stepwise multivariable logistic regression analysis. Variables examined included age, sex, number, type and currency of reoperations, preoperative conduction disturbances, preoperative catheterization values, presence of mitral annular calcification, preoperative New York Heart Association (NYHA) class, number of bypass grafts performed, hypertension or diabetes mellitus, preoperative prosthetic endocarditis, sternal reentry complications, postoperative low cardiac output, postoperative bleeding, perfusion and aortic crossclamp times, usage, type and volume of cardioplegic solutions, lowest hematocrit and temperature during cardiopulmonary bypass, need for postoperative transfusion, and emergency operation. Follow-up by clinic examination or telephone contact was complete in $96 \%$ of patients (100\% in the PPI group).

\section{Results}

The mean age for the entire group was $56 \pm 14$ years, with a range of 3 to 90 years. Mean ages for the PPI and nonpaced groups were $59.8 \pm 13.9$ years and $55.7 \pm 15.0$ years, respectively $(p=0.05)$. The male/female ratio was 313:245 (1.3:1). Although a slight female predominance was seen in the PPI group, it was not significantly different from the gender ratio of patients who were not paced. The types of operative procedures are summarized in Table I. The number of repeat operations in most instances was higher in the permanent pacing group (Table II). Causes of nonfatal morbidity and operative deaths are outlined in Tables III and IV, respectively. In the group that was not paced, tachyarrhythmias (ventricular fibrillation, 7 deaths; ventricular tachycardia, 1 death; atrial fibrillation, 2 deaths) contributed to operative mortality in 10 of 504 patients $(2.0 \%)$. Only one patient was paced temporarily at the time of death. No bradyarrhythmia precipitated death in this group. In the PPI 
Table III. Major nonfatal postoperative complications*

\begin{tabular}{lclc}
\hline & $\begin{array}{c}\text { Nonpaced } \\
\text { group } \dagger \\
(\%)\end{array}$ & $p$ Valueई & $\begin{array}{c}\text { Permanent } \\
\text { pacemakert } \\
(\%)\end{array}$ \\
\hline Arrhythmia & $65(16.1)$ & 0.00001 & $42(100)$ \\
Low cardiac output & $29(7.2)$ & 0.6 & $4(9.5)$ \\
Bleeding & $25(6.2)$ & 0.8 & $3(7.1)$ \\
Pleural effusion & $22(5.4)$ & 0.02 & $6(14.3)$ \\
Pneumonia & $21(5.2)$ & 0.1 & $0(0)$ \\
Cerebrovascular accident & $20(5.0)$ & 0.1 & $0(0)$ \\
Wound infection & $18(4.5)$ & 0.9 & $2(4.8)$ \\
Respiratory insufficiency & $13(3.2)$ & 0.0007 & $8(19.0)$ \\
Renal failure & $4(1.0)$ & 0.002 & $3(7.1)$
\end{tabular}

The incidence of the following complications was less than $4 \%$ in both groups: brachial plexus injury, congestive heart failure, cholecystitis, delirium, systemic emboli, empyema, endocarditis, femoral neuropathy, fever of unknown origin, gastrointestinal bleeding, groin lymphocele, jaundice, intraaortic balloon injuries, leg cellulitis, liver failure, myocardial infarction, phlebitis, pulmonary emboli, phrenic nerve injury, pneumothorax, postcardiotomy syndrome, retained vascular catheter, seizures, smal bowel obstruction, splenic infarct, urinary tract infection, and urine retention.

*Some had multiple complications.

$\dagger n=403$.

$\ddagger n=42$.

$\S \chi^{2}$ test of association.

cohort, 10 of 12 patients $(83.3 \%)$ who died in the hospital had complete heart block compared with 18 of $42(42.9 \%)$ survivors $(p=0.01)$. However, no deaths in this group were attributed directly to the bradyarrhythmia that required permanent pacing.

Some type of conduction defect was seen preoperatively in 159 of 504 patients $(31.5 \%)$ that did not require PPI (incomplete or complete right bundle branch block, $57.7 \%$ of this subtotal; left bundle branch block, $25.0 \%$; nonspecific intraventricular delay, $15.4 \%$; isolated left anterior fascicular block, $1.9 \%$ ). These defects remained stable throughout the perioperative period. A conduction defect less than complete heart block was present in 15 of 54 patients $(27.8 \%)$ who required postoperative permanent pacing (Table V). These preoperative conduction abnormalities were not statistically different in number between the group that was not paced and the PPI group. In patients older than 61 years of age, some type of incomplete preoperative block was present in 9 of 29 patients $(31.0 \%)$ compared with 6 of 25 patients $(24.0 \%)$ who were 61 years of age and older $(p=0.6)$. In PPI survivors, 14 of 42 patients $(33.3 \%)$ had some type of preoperative block compared with 1 of 12 patients $(8.3 \%)$ who died in the hospital $(p=0.09)$. Predominant postoperative rhythms necessitating PPI included symptomatic sinus bradycardia with rates less than 45 to
Table IV. Factors contributing to operative death**

\begin{tabular}{lcc}
\hline & $\begin{array}{c}\text { Nonpaced } \\
\text { groupt } \\
(\%)\end{array}$ & $\begin{array}{c}\text { Permanent } \\
\text { pacing } \% \\
(\%)\end{array}$ \\
\hline Deaths & $101(20.0)$ & $12(22.2)$ \\
Low cardiac output & $63(12.5)$ & $4(7.4)$ \\
Bleeding & $26(5.2)$ & $2(3.7)$ \\
Renal failure & $15(3.0)$ & $2(3.7)$ \\
Respiratory insufficiency & $12(2.4)$ & $3(5.6)$ \\
Cardiovascular accident & $11(2.2)$ & $2(3.7)$ \\
Sepsis & $11(2.2)$ & $2(3.7)$ \\
Tachyarrhythmias & $10(2.0)$ & $2(3.7)$ \\
\hline
\end{tabular}

The following accounted for less than $2 \%$ of fatal complications: cholecystitis, congestive heart failure, endocarditis, gastrointestinal bleeding, hepatic failure, myocardial infarction, pneumonia, pulmonary emboli, systemic emboli, and wound infections.

*Some had multiple causes; the causes of death did not differ statistically between the two groups ( $\chi^{2}$ test of association).

$\dagger n=504$.

$\ddagger n=54$.

50 beats/min in 10 patients (18.5\%), atrial fibrillation with a similar slow ventricular response in 11 patients $(20.4 \%)$, and complete heart block (CHB) in 29 patients $(53.7 \%)$.

Pacemaker insertion occurred during the same hospitalization in 44 of 54 patients $(81.5 \%) ; 10$ of 42 survivors $(23.8 \%)$ had a pacemaker placed more than 1 year after the repeat cardiac operation (Table VI). In this late cohort of 10 patients, PPI was required to control symptomatic sinus bradycardia and atrial fibrillation with bradycardia; no late $\mathrm{CHB}$ was seen. Epicardial leads placed at the time of reoperation were used in 30 patients $(55.6 \%)$; the transvenous route was used in 24 patients $(44.4 \%)$. VVI units were used in 46 patients $(85.2 \%)$; DDD in 6 patients $(11.1 \%)$, and DVI in 2 patients $(3.7 \%)$. Dual-chamber pacing could not be used in 35 of 54 patients $(64.8 \%)$ for the following reasons: atrial fibrillation, 27 of 35 patients $(77.1 \%)$; tricuspid valve prosthesis, 3 of 35 patients $(8.6 \%)$; pacemaker implantation before the availability of dual-chamber units, 5 of 35 patients $(14.3 \%)$. Placement of a VVI unit in lieu of a DDD system represented surgeons' preference in 6 of 54 patients (11.1\%). Table VII presents threshold data for these pacing systems. Early revision of epicardial to transvenous leads was required for rising thresholds in three patients and failure to sense in one patient. A second maintenance pacemaker operation was required at a mean time of 3.7 years in 13 of 42 patients $(31.0 \%)$ and a third in 3 of 42 patients $(7.1 \%)$ at a mean time of 2.4 years from the second operation. Although two thoracotomies were performed to place additional 
Table V. Preoperative conduction defects

\begin{tabular}{|c|c|c|c|c|c|c|}
\hline \multirow[b]{2}{*}{ Type of block } & \multirow{2}{*}{$\begin{array}{l}\text { All PPI } \\
\text { patients } \\
(n=54)\end{array}$} & \multirow{2}{*}{$\begin{array}{c}\text { Those with } \\
\text { postoperative } C H B \\
(n=29)\end{array}$} & \multirow[b]{2}{*}{$\begin{array}{l}\text { Survivors } \\
(n=42)\end{array}$} & \multirow{2}{*}{$\begin{array}{l}\text { Operative } \\
\text { deaths } \\
(n=12)\end{array}$} & \multicolumn{2}{|c|}{ At operation } \\
\hline & & & & & $\begin{array}{c}\leq 61 y r \\
(n=25)\end{array}$ & $\begin{array}{c}>61 y r \\
(n=29)\end{array}$ \\
\hline RBBB & 3 & 1 & 3 & 0 & 1 & 2 \\
\hline LBBB & 6 & 6 & 5 & 1 & 3 & 3 \\
\hline RBBB, LAFB & 3 & 2 & 3 & 0 & 1 & 2 \\
\hline IVCD & 2 & 0 & 2 & 0 & 1 & 1 \\
\hline
\end{tabular}

$R B B B$, Right bundle branch block; $L B B B$, left bundle branch block; $L A F B$, left anterior fascicular block; IVCD, intraventricular conduction delay not otherwise specified.

Table VI. Conduction defects in early and late permanent pacemaker implantations

\begin{tabular}{|c|c|c|c|c|}
\hline \multicolumn{2}{|c|}{ Early pacemaker implantations rhythm (mean, 9.6 days) } & \multicolumn{3}{|c|}{ Late pacemaker implantations rhythm (mean, 5.0 yrs) } \\
\hline Preoperative (no.) & Postoperative (no.) & Preoperative & Postoperative (no.) & $\begin{array}{l}\text { At time of late pacemaker } \\
\text { implantation (no.) }\end{array}$ \\
\hline \multirow{4}{*}{$\begin{array}{l}\text { SR without conduction } \\
\text { defects* (16) }\end{array}$} & CHB (10) & SR & Sinus bradycardia (1) & Second degree heart block (1) \\
\hline & Sinus bradycardia (3) & & & \\
\hline & AF with bradycardia (2) & & & \\
\hline & Second degree heart block (1) & SR & SR, LBBB (1) & Sinus bradycardia, LBBB (1) \\
\hline SR, LBBB (5) & CHB (5) & SR & $\mathrm{AF}(1)$ & AF with bradycardia (1) \\
\hline \multirow[t]{2}{*}{ SR, RBBB, LAFB (3) } & CHB (2) & $\mathrm{AF}$ & $\mathrm{AF}(3)$ & AF with bradycardia (3) \\
\hline & Sinus bradycardia (1) & $\mathrm{AF}$ & SSS (2) & AF with bradycardia (2) \\
\hline SR, IVCD (1) & SSS (1) & & & \\
\hline \multirow{2}{*}{$\begin{array}{l}\text { AF without conduction } \\
\text { defects (13) }\end{array}$} & CHB (10) & SSS & SSS (2) & SSS (2) \\
\hline & AF with bradycardia (3) & & & \\
\hline $\mathrm{AF}, \mathrm{LBBB}(1)$ & CHB (1) & & & \\
\hline \multirow[t]{3}{*}{$\mathrm{AF}, \mathrm{RBBB}(3)$} & CHB (1) & & & \\
\hline & Junctional bradycardia (1) & & & \\
\hline & AF with bradycardia (1) & & & \\
\hline AF, LAFB (1) & Junctional bradycardia (1) & & & \\
\hline AF, IVCD (1) & AF with bradycardia (1) & & & \\
\hline
\end{tabular}

$S R$, Sinus rhythm; $A F$, atrial fibrillation; $L B B B$, left bundle branch block; $R B B B$, right bundle branch block; $L A F B$, left anterior fascicular block; SSS, sick sinus syndrome; $I V C D$, intraventricular conduction delay.

epicardial leads in patients with tricuspid valve replacement, no significant morbidity or deaths were seen in these later procedures.

A multivariable analysis showed that the need for PPI was more common in those patients with tricuspid valve annuloplasty/replacement associated with aortic/mitral valve replacements, preoperative prosthetic endocarditis, greater number of reoperations, lowest core temperature during cardiopulmonary bypass, and advanced age. The final model from a stepwise logistic regression analysis is comprised of those variables (Table VIII). A univariable analysis demonstrated an additional relationship for multiple valve replacements, increased cardiopulmonary bypass/aortic crossclamp times, and isolated aortic valve replacement (Table IX).

At a mean follow-up time of 6.0 years (range, 1 month to 18 years), patients who received PPI and patients who were not paced exhibited NYHA class
I and II symptoms in $93.6 \%$ and $90.9 \%$ of patients, respectively $(p=0.6)$. Continuous pacing was seen in 28 of 42 patients $(66.7 \%)$ at the last follow-up. CHB developed in 14 of 34 patients $(41.2 \%)$ with a lesser block at the initial PPI. CHB reverted to a nonpaced rhythm in six patients $(14.3 \%)$. This change occurred on average at 40 months (range, 2 months to 8 years). Kaplan-Meier survival analysis showed similar curves for both groups up to 10 years after the surgical procedure.

Survival for PPI patients was $83 \%$ at 5 years and $51 \%$ at 10 years; in the cohort that was not paced, $84 \%$ of patients were alive at 5 years and $60 \%$ at 10 years (Fig. 1). The most common causes of late death in both cohorts included documented congestive heart failure, cancer, and tachyarrhythmias. Of the 42 PPI survivors, $32(76.2 \%)$ were pacemaker dependent at the last follow-up.

In 24 late deaths, most patients were pacemaker 
Table VII. Ventricular threshold values for pacemaker insertion after reoperative cardiac procedures

\begin{tabular}{lcccc}
\hline & \multicolumn{4}{c}{ Leads } \\
\cline { 2 - 5 } & $\begin{array}{c}\text { Initial } \\
\text { pacemaker } \\
(\text { all })\end{array}$ & $\begin{array}{c}\text { Epicardial } \\
(n=30)\end{array}$ & $\begin{array}{c}p \\
\text { Value }^{*}\end{array}$ & $\begin{array}{c}\text { Transvenous } \\
(n=24)\end{array}$ \\
\hline Current (mA) & 2.9 & 4.7 & 0.004 & 1.4 \\
Voltage (V) & 1.3 & 2.1 & 0.002 & 0.6 \\
Resistance (ohm) & 512 & 464 & 0.2 & 548 \\
R wave (mV) & 10.8 & 9.6 & 0.4 & 11.9 \\
\hline
\end{tabular}

*Two-sample unpaired $t$ test.

Table VIII. Logistic regression model of factors related to permanent pacing after reoperative cardiac surgery

\begin{tabular}{|c|c|c|c|c|}
\hline \multirow[b]{2}{*}{ Variable } & \multirow{2}{*}{$\begin{array}{l}\text { Odds } \\
\text { ratio }\end{array}$} & \multicolumn{2}{|c|}{$\begin{array}{l}95 \% \\
\text { Confidence } \\
\text { ratios }\end{array}$} & \multirow{2}{*}{$\begin{array}{c}p \\
\text { Values }\end{array}$} \\
\hline & & Upper & Lower & \\
\hline $\begin{array}{l}\text { Tricuspid annuloplasty/ } \\
\text { replacement with } \\
\text { aortic/mitral valve } \\
\text { replacement }\end{array}$ & 4.28 & 9.94 & 1.84 & 0.001 \\
\hline $\begin{array}{l}\text { Preoperative prosthetic } \\
\text { endocarditis }\end{array}$ & 3.31 & 8.27 & 1.33 & 0.01 \\
\hline $\begin{array}{l}\text { Greater number of reop- } \\
\text { erations }\end{array}$ & 1.71 & 2.72 & 1.08 & 0.01 \\
\hline $\begin{array}{l}\text { Lowest core temperature } \\
\text { during cardiopulmo- } \\
\text { nary bypass }\end{array}$ & 1.14 & 1.25 & 1.05 & 0.002 \\
\hline Advanced age & 1.03 & 1.06 & 1.01 & 0.01 \\
\hline
\end{tabular}

dependent. In those whose cause of death was not related to an arrhythmia, 8 of 10 patients $(80.0 \%)$ were pacemaker dependent; 7 of 10 patients (70.0\%) died of unknown causes, and 3 of $4(75.0 \%)$ documented arrhythmic deaths demonstrated pacemaker dependency during follow-up. Late cardiac arrest from ventricular tachyarrhythmias was seen in 6 of 403 patients who were not paced $(1.5 \%)$ compared with 4 of $42(9.5 \%)$ in the group with PPI $(p=0.001)$.

\section{Discussion}

New rhythm disturbances and conduction defects are relatively common after most cardiac procedures that require cardiopulmonary bypass. These problems include sinus node dysfunction, various fascicular blocks, and complete atrioventricular block. Fortunately most are self-limiting and harm-
Table IX. Univariable analysis of factors possibly related to permanent pacemaker need after reoperative cardiac surgery

\begin{tabular}{lccc}
\hline & $\begin{array}{c}\text { Nonpaced } \\
\text { group } \\
(n=504)\end{array}$ & $\begin{array}{c}\text { Permanent } \\
\text { pacing group } \\
(n=54)\end{array}$ & $\begin{array}{c}p \\
\text { Values }\end{array}$ \\
\hline $\begin{array}{l}\text { Patients with multiple valve } \\
\text { replacement }(\%)\end{array}$ & 8.5 & 25.9 & 0.001 \\
$\begin{array}{l}\text { Cardiopulmonary bypass } \\
\text { time* (min) }\end{array}$ & $138 \pm 90$ & $150 \pm 55$ & 0.003 \\
$\begin{array}{l}\text { Aortic crossclamp time* } \\
\quad(\text { min) }\end{array}$ & $61 \pm 32$ & $71 \pm 25$ & 0.01 \\
$\begin{array}{l}\text { Patients with isolated aortic } \\
\text { valve replacement }(\%)\end{array}$ & 12.1 & 22.2 & 0.04 \\
$\begin{array}{l}* \text { Mean } \pm \text { standard deviation. } \\
\text { Men }\end{array}$ & & & \\
\hline
\end{tabular}

less and disappear before hospital discharge. Some, however, are permanent and require either prolonged surveillance for malignant rhythm development $^{2,20}$ or PPI. Factors leading to these conduction defects identified by multivariate analyses are advanced age (especially older than 64 years of age), total cardiopulmonary bypass and aortic crossclamp times, significant left main coronary artery stenosis, right coronary artery occlusion with significant stenosis of the left anterior descending coronary artery, number of bypassed coronary arteries, currency of operation, presence of preoperative conduction defects, concomitant left ventricular aneurysmectomy, use of cold cardioplegia, and the maximal degree of myocardial cooling. ${ }^{1,4,6,8,23,24}$ Other elements thought to be related to the genesis of these rhythm disturbances include long-standing hypertension, atherosclerotic lesions jeopardizing flow to the first septal perforating coronary artery, number of diseased coronary arteries, preoperative use of digoxin, $\beta$-blockers or calcium channel blockers, previous inferior wall myocardial infarction, presence of mitral annular or aortic valve calcification, left ventricular ejection fraction, type of cardioplegia used, adequacy of myocardial protection, valvular surgery especially involving the tricuspid valve, less frequent use of the internal thoracic artery graft, the serum potassium level at the time of aortic crossclamp release, high postoperative creatine kinase MB levels, perioperative myocardial infarction, perioperative low cardiac output, postoperative atrial fibrillation, and no identifiable factors. ${ }^{4-8,10,12,15,17,21-23,25}$ Conditions related to the specific need for permanent pacing after cardiac surgical procedures include postoperative atrial fibrillation, preoperative conduction defects (sinus and atrioventricular node dysfunction 


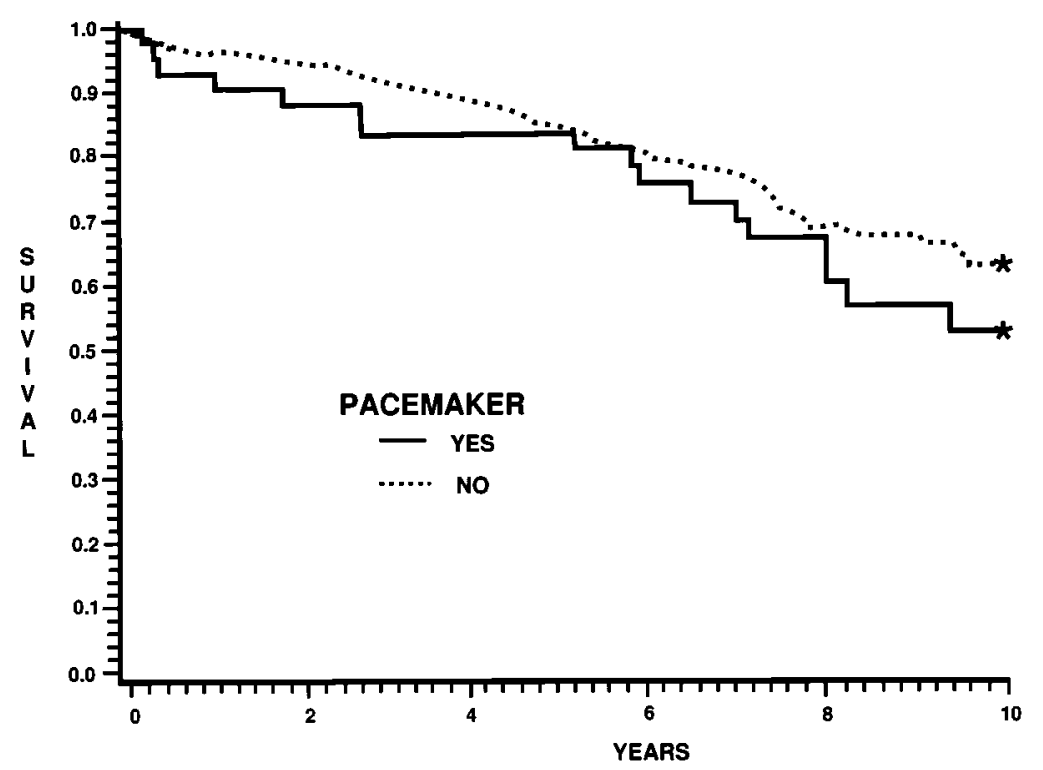

Fig. 1. Kaplan-Meier survival curves for paced and nonpaced cohorts after reoperative cardiac surgery.

* Log rank $p$ value shows no significant difference in curves.

including bundle branch blocks), advanced age, dense calcium in the aortic anulus with or without mitral annular calcification, valvular operations especially involving the tricuspid valve, poor myocardial protection, and no obvious factors. ${ }^{7,10,11,15,18,25}$ The increased need for PPI after orthotopic heart transplantation may reflect organ rejection, operative trauma, prolonged perioperative ischemic time, drug use, or combinations thereof. $3,13,16$

Conduction injury leading to the need for permanent pacing in patients undergoing reoperations has not been well documented. Many of the conditions detailed earlier can be seen in these patients.

In a series of 5942 mixed cardiac procedures, ${ }^{10}$ 123 patients $(2.1 \%)$ required PPI. Redo procedures accounted for $22 \%$ of these pacemaker implantations. In 227 patients surviving repeat valve surgery, ${ }^{26} 18(7.9 \%)$ required permanent pacemakers. We thought that preoperative endocarditis and first-degree atrioventricular block increased the need for PPI. Because some valvular prostheses have limited viability, the subsequent need for reoperation may impose conditions that can damage the conduction system. The atrioventricular node lies close to the noncoronary cusp of the aortic valve, the posterior-medial commissure of the anterior mitral leaflet, and the septal leaflet of the tricuspid valve. Debridement of annular tissue at these areas decreases the distance between the atrioventricular node and anchoring sutures, thereby increasing the chance for conduction injury. Careful attention to this anatomy combined with judicious debridement and choice of a valvular prosthesis commensurate with the clinical setting may lessen this problem.

Although systemic hypothermia appears to have a salutary effect on myocardial protection during aortic crossclamping, injury to the conduction system may parallel the level of reduced temperature. In one series, ${ }^{23}$ cold myocardial "protection" (core cooling to $28^{\circ} \mathrm{C}$ plus cold cardioplegia) produced greater injury to the conduction system than a warm delivery system (normothermic perfusion and cardioplegia). Because all patients receiving hypothermic perfusion were cooled to the same core temperature, it is difficult to ascertain whether this injury resulted from systemic or cardioplegia cooling. In our patients, cardioplegia temperatures were kept around $10^{\circ} \mathrm{C}$, but the core temperature varied by surgeons' preference. Significantly, the degree of core cooling was found to be an independent predictor of permanent pacemaker need, with a breakpoint for conduction injury below $21^{\circ} \mathrm{C}$. It is difficult to understand how core cooling leads to conduction injury when this phenomenon is not seen regularly with lower temperature levels achieved during profound hypothermia and circulatory arrest. Nevertheless, avoidance of hypothermia levels below $21^{\circ} \mathrm{C}$ may offer some protection against the development of postoperative bradyarrhythmias requiring PPI 
during reoperative cardiac procedures. Because permanent epicardial leads were placed in many of our patients at the time of the operation when significant bradycardia was encountered, implantation of a permanent generator in the immediate postoperative period was relatively simple. Pacing thresholds for these leads were significantly higher than transvenous leads, leading in some instances to the need for revision. Because most currently implanted pacing units have sophisticated telemetry, frequent observation of epicardial leads should signal abnormally rising thresholds. Unless a tricuspid prosthesis has been implanted in this setting, conversion to a transvenous pacing system remains the procedure of choice.

In a collected series of 2989 patients from the general population who received a pacemaker unrelated to any cardiac surgical procedure, ${ }^{27-30}$ the actuarial survival at 5 years ranged from $41 \%$ to $67 \%$. Most patients had mean ages between 67 and 80 years. In cohorts who received a pacemaker before they were 66 years of age, the 5-year survival was approximately $70 \%$ to $75 \%$. In our PPI group, the mean age was 59.8 years with a 5 -year survival of $83 \%$. Survival time in the redo cardiac surgical group that did not require pacing also compared favorably with these values. PPI after redo cardiac surgical procedures does not seem to significantly affect longevity.

We thank Jennifer Cholewa for her assistance in the preparation of this manuscript.

\section{REFERENCES}

1. Baerman JM, Kirsh MM, de Buitleir M, Hyatt L, Juni JE, Pitt B, et al. Natural history and determinants of conduction defects following coronary artery bypass surgery. Ann Thorac Surg 1987;44:150-3.

2. Bateman TM, Weiss MH, Czer LSC, Conklin CM, Kass RM, Stewart ME, et al. Fascicular conduction disturbances and ischemic heart disease: adverse prognosis despite coronary revascularization. J Am Coll Cardiol 1985;5:632-9.

3. Blanche C, Czer LSC, Trento A, Fishbein MC, Doan D, Jordan S, et al. Bradyarrhythmias requiring pacemaker implantation after orthotopic heart transplantation: association with rejection. J Heart Lung Transplant 1992;11:446-52.

4. Caretta Q, Mercanti CA, De Nardo D, Chiarotti F, Scibilia G, Reale A, et al. Ventricular conduction defects and atrial fibrillation after coronary artery bypass grafting: multivariate analysis of preoperative, intraoperative and postoperative variables. Eur Heart J 1991;12:1107-11.

5. Caspi Y, Safadi T, Ammar R, Elamy A, Fishman NH, Merin $\mathrm{G}$. The significance of bundle branch block in the immediate postoperative electrocardiograms of patients undergoing coronary artery bypass. J Thorac Cardiovasc Surg 1987;93: 442-6.

6. Chu A, Califf RM, Pryor DB, McKinnis RA, Harrell FE Jr, Lee KL, et al. Prognostic effect of bundle branch block related to coronary artery bypass grafting. Am J Cardiol 1987;59:798-803.

7. Creswell LL, Schuessler RB, Rosenbloom M. Cox JL. Hazards of postoperative atrial arrhythmias. Ann Thorac Surg 1993;56:539-49.

8. Emlein G, Huang SKS, Pires LA, Rofino K, Okike ON, Vander Salm TJ. Prolonged bradyarrhythmias after isolated coronary artery bypass graft surgery. Am Heart J 1993;126: 1084-90.

9. Gaillard D, Lespinasse P, Vanetti A. Cardiac pacing and valvular surgery. PACE Pacing Clin Electrophysiol 1988;11: 2142-8.

10. Goldman BS, Hill TJ, Weisel RD, Scully HE, Mickleborough LL, Pym J, et al. Permanent cardiac pacing after open-heart surgery: congenital heart disease. PACE Pacing Clin Electrophysiol 1985;8:732-9.

11. Goldman BS, Williams WG, Hill T, Hesslein PS, McLaughlin PR, Trusler GA, et al. Permanent cardiac pacing after open heart surgery: congenital heart disease. PACE Pacing Clin Electrophysiol 1985;8:732-9.

12. Gundry SR, Dequeira A, Coughlin TR, McLaughlin JS. Postoperative conduction disturbances: a comparison of blood and crystalloid cardioplegia. Ann Thorac Surg 1989; 47:384-90.

13. Jacquet L, Ziady G, Stein K, Griffith B, Armitage J, Hardesty $\mathrm{R}$, et al. Cardiac rhythm disturbances early after orthotopic heart transplantation: prevalence and clinical importance of the observed abnormalities. J Am Coll Cardiol 1990;16:832-7.

14. Kallis P, Unsworth-White J, Munsch C, Gallivan S, Smith EEJ, Parker DJ, et al. Disability and distress following cardiac surgery in patients over 70 years of age. Eur J Cardiothorac Surg 1993;7:306-12.

15. Keefe DL, Griffin JC, Harrison DC, Stinson EB. Atrioventricular conduction abnormalities in patients undergoing isolated aortic or mitral valve replacement. PACE Pacing Clin Electrophysiol 1985;8:393-8.

16. Montero JA, Anguita M, Concha M, Villarrubia A, Garcia J, Arizon JM, et al. Pacing requirements after orthotopic heart transplantation: incidence and related factors. J Heart Lung Transplant 1992;11:799-802.

17. Mosseri M, Meir G, Lotan C, Hasin Y, Applebaum A, Rosenheck $\mathrm{S}$, et al. Coronary pathology predicts conduction disturbances after coronary artery bypass grafting. Ann Thorac Surg 1991;51:248-52.

18. Otaki M. Permanent cardiac pacing after cardiac operations. Artif Organs 1993;17:346-9.

19. Sharma GVRK, Kirdar JA, Folland ED, Josa M, Khuri SF, Parisi AF. Conduction abnormalities following coronary bypass surgery: predictive role of coronary lesions [Abstract]. J Am Coll Cardiol 1984;3:529.

20. Thomas JL, Dickstein RA, Parker FB Jr, Potts JL, Poirier RA, Fruehan CT, et al. Prognostic significance of the development of left bundle conduction defects following aortic valve replacement. J Thorac Cardiovasc Surg 1982;84:382-6.

21. Wexelman W, Lichstein E, Cunningham JN, Hollander G, Greengart A, Shani J. Etiology and clinical significance of new fascicular conduction defects following coronary bypass surgery. Am Heart J 1986;111:923-7. 
22. Baraka AS, Taha SK, Yazbeck VK, Rizkallah PA, Zughbi JP, Aouad MJ, et al. Transient atrioventricular block after release of aortic cross-clamp. Anesth Analg 1995;80:54-7.

23. Flack JE III, Hafer J, Engelman RM, Rousou JA, Deaton DW, Pekow P. Effect of normothermic blood cardioplegia on postoperative conduction abnormalities and supraventricular arrhythmias. Circulation 1992;86(Suppl):II385-92.

24. Hippelainen M, Mustonen P, Manninen H, Rehnberg S. Predictors of conduction disturbances after coronary bypass grafting. Ann Thorac Surg 1994;57:1284-8.

25. Nair CK, Sketch MH, Ahmed I, Thomson W, Ryschon K, Woodruff MP, et al. Calcific valvular aortic stenosis with and without mitral annular calcium. Am J Cardiol 1987;60:86570 .

26. Jaeger FJ, Trohman RG, Brener S, Loop F. Permanent pacing following repeat cardiac valve surgery. Am J Cardiol 1994;74:505-7.
27. Alpert MA, Curtis JJ, Sanfelippo JF, Flaker GC, Walls JT, Mukerji $\mathrm{V}$, et al. Comparative survival after permanent ventricular and dual chamber pacing for patients with chronic high degree atrioventricular block with and without preexistent congestive heart failure. J Am Coll Cardiol 1986;7:92532.

28. Muller C, Cernin J, Glogar D, Laczkovics A, Mayr H, Scheibelhofer W, et al. Survival rate and causes of death in patients with pacemakers: dependence on symptoms leading to pacemaker implantation. Eur Heart J 1988;9:1003-9.

29. Shen WK, Hammill SC, Hayes DL, Packer DL, Bailey KR, Ballard DJ, et al. Long-term survival after pacemaker implantation for heart block in patients $\geq 65$ years. Am J Cardiol 1994;74:560-4

30. Simon AB, Janz N. Symptomatic bradyarrhythmias in the adult: natural history following ventricular pacemaker implantation. PACE Pacing Clin Electrophysiol 1982;5:372-83.

\section{ON THE MOVE?}

Don't miss a single issue of the journal! To ensure prompt service when you change your address, please photocopy and complete the form below.

Please send your change of address notification at least six weeks before your move to ensure continued service. We regret we cannot guarantee replacement of issues missed due to late notification.

\section{JOURNAL TITLE:}

Fill in the title of the journal here.

OLD ADDRESS:

Affix the address label from a recent issue of the journal here.

\section{NEW ADDRESS:}

Clearly print your new address here.

Name

Address

City/State/ZIP
COPY AND MAIL THIS FORM TO:

Periodical Subscription Services

Mosby, Inc.

11830 Westline Industrial Dr.

St. Louis, MO 63146-3318
OR FAX TO:

314-432-1158

N/ Mosby
OR PHONE:

1-800-453-4351

Outside the U.S., call

314-453-4351 